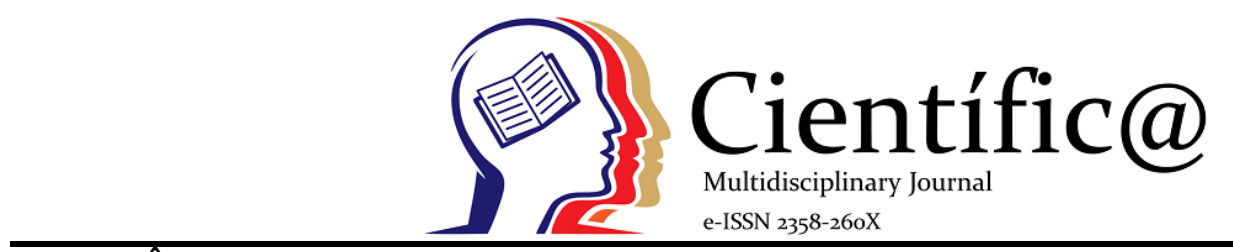

\title{
INFLUÊNCIA DO TAMANHO E MASSA DAS SEMENTES NA GERMINAÇÃO DE SERIGUELA (SPONDIAS PURPUREA L.)
}

\author{
INFLUENCE OF THE SIZE AND MASS SEEDS SERIGUELA GERMINATION (SPONDIAS PURPUREA L.) \\ Cristiano Pereira da Silva ${ }^{1 *}$,Jonas Souza Correa ${ }^{2}$, Margareth Ferreira Pistori ${ }^{3}$; Cleviana Goulart \\ Afonso ${ }^{4}$
}

\footnotetext{
${ }^{1}$ Universidade Estadual de Mato Grosso do Sul - UEMS - cpsilva.cetec@gmail.com

${ }^{2}$ Professor da UEMS e Estácio de Sá de Campo Grande MS

${ }^{3}$ Secretaria Municipal de Educação e Cultura SEMEC

${ }^{4}$ Faculdade Estácio de Sá de Campo Grande/MS - Engenharia Ambiental e Sanitária
}

Info

Recebido: 04/2021

Publicado: 06/2021

DOI: $10.37951 / 2358-260 X .2021 v 8 i 1.5649$

ISSN: 2358-260X

Palavras-Chave
germinação, sementes, seriguela.
Keywords:
germination, seeds, seriguela.

\begin{abstract}
Resumo
Objetivo deste trabalho é avaliar a influência do tamanho e massa das sementes de seriguela e sua relação ao vigor das sementes nos diferentes tipos de substratos. Foram utilizadas sementes de seriguela (Spondias purpurea L.), obtidas de plantas matrizes com aproximadamente 17 anos de idade. As sementes foram classificadas em dois grupos, tamanho e massa, utilizando paquímetro e balança convencional, foram classificadas em sementes pequenas, grandes, menor e maior massa. Após o processo de classificação as sementes foram semeadas em saquinhos plásticos de $1 \mathrm{~kg}$, contendo como substrato: a) terra úmida + esterco bovino na proporção $3: 1$; b) areia de construção + esterco bovino na proporção 3:1, mantidos viveiro
\end{abstract} sombreado em ambiente aberto. Após 60 dias, os foram obtidos os resultados para porcentagem de germinação, índice de velocidade de germinação, comprimento das plântulas e massa seca das plântulas. De acordo com os resultados, sementes maiores e com maior massa, apresentaram os melhores resultados para porcentagem de germinação (81,62\%), índice de velocidade de germinação $(8,45)$, comprimento médio das plântulas $(10,25 \mathrm{~cm}) e$ massa seca das plântulas $(0,874 \mathrm{~g})$. Concluímos que o tamanho e a massa das sementes influenciam na porcentagem de germinação, na velocidade de germinação e comprimento e massa das plântulas.

\begin{abstract}
The objective of this work is to evaluate the influence of the size and mass of buttercup seeds and their relation to the vigor of the seeds in the different types of substrates. Seriguela seeds (Spondias purpurea L.), obtained from mother plants with approximately 17 years of age, were used. The seeds were classified into two groups, size and mass, using a caliper and conventional scale, and were classified into small, large, smaller and larger seeds. After the classification process, the seeds were sown in $1 \mathrm{~kg}$ plastic bags, containing as substrate: a) moist soil + bovine manure in a 3: 1 ratio; b) construction sand + bovine manure in a 3: 1 ratio, kept in a shaded pond in an open environment. After 60 days, the results for germination percentage, germination speed index, seedling length and seedling dry mass were obtained. According to the results, larger seeds with greater mass, showed the best results for germination percentage (81.62\%), germination speed index (8.45), average seedling length (10.25cm) and mass dryness of seedlings $(0.874 \mathrm{~g})$. We conclude that the size and mass of the seeds influence the percentage of germination, the speed of germination and the length and mass of the seedlings.
\end{abstract}

\section{Introdução}

O gênero Spondias (Anacardiaceae) é composto por aproximadamente 15 espécies de frutíferas que são facilmente encontradas nas Américas, Central e do Sul, incluindo o Brasil (MALDONADOASTUDILLO et al., 2014, LIMA et al., 2018). A serigueleira é uma fruteira tropical encontrada nos países da América Tropical, incluindo o Brasil, sendo distribuída em praticamente todo o território do país, com maior presença região Nordeste nos pomares extrativista. Apesar do elevado potencial econômico e grande aceitação do fruto para consumo in natura, a serigueleira não dispõe de sistema de produção (LIRA JUNIOR et al., 2014; ALMEIDA et al., 2017). 
No nordeste brasileiro, as frutíferas do gênero Spondias são mais difundidas principalmente as espécies: Spondias mombin L. (cajazeira), Spondias purpurea L. (serigueleira), Spondias cytherea Sonn. (cajaraneira), Spondias tuberosa Arr. Câm. (umbuzeiro) e Spondias spp. (umbu-cajá e umbuguela), todas são árvores frutíferas tropicais largamente exploradas (ALMEIDA et al., 2017; SOUZA et al., 2018).

A serigueleira se destaca por ser muito atrativa para os pomares domiciliares e de pequeno porte nos quintais domésticos, e embora não haja grande produção a nível comercial e não figure entre as grandes estatísticas agrícolas, ainda assim possui importância econômica e social, especialmente nos mercados regionais do Norte e Nordeste do Brasil pois é muito apreciada pelo sabor e qualidade do fruto, sendo típico de regiões semiáridas do Agreste e do Sertão (LEDERMAN et al., 2008; SACRAMENTO \& SOUZA, 2009; FERREIRA et al., 2015; ROCHA et al., 2019).

O método de propagação por semente é muito comum na produção de mudas de seriguela, pois usam o endocarpo, comumente chamado de "caroço," na propagação sexuada. Embora algumas espécies do gênero Spondias, possuam mais de uma semente por endocarpo, para a seriguela, pode ocorrer a formação de uma semente que não irá germinar. Existem relatos de que a seriguela, propagadas por sementes obedecendo as recomendações técnicas (profundidade de $3 \mathrm{~cm}$, colocando-se o endocarpo na posição vertical com a parte proximal voltada para baixo) podem apresentar baixa porcentagem de germinação e índice de velocidade de germinação insatisfatório (LEDERMAN et al., 2008; SACRAMENTO \& SOUZA, 2009).

Algumas espécies como a seriguela, não produzem grãos de pólen férteis e nem sementes viáveis (MACIA et al., 2000; MARTINS et al., 2003;
SACRAMENTO et al., 2009). A classificação das sementes por tamanho ou massa é uma estratégia adotada para uniformizar a emergência das plântulas, obtendo mudas de tamanho semelhante ou de maior vigor das sementes. Sementes maiores ou de maior densidade em uma mesma espécie são, potencialmente, mais vigorosas do que as menores e menos densas e originam plântulas mais desenvolvidas (CARVALHO e NAKAGAWA, 2000). A qualidade fisiológica das sementes tem sido caracterizada pela germinação e pelo vigor. $\mathrm{O}$ vigor das sementes é a soma de atributos que confere á semente potencial para germinar, emergir e resultar rapidamente em plântulas normais sob ampla diversidade de condições ambientais (HÖFS et al., 2004). Diante do exposto o objetivo deste trabalho é verificar a influência do tamanho e massa das sementes sobre o vigor de seriguela em diferentes tipos de substratos.

\section{Material e Métodos}

O presente trabalho foi realizado no município de Murutinga do Sul (SP), numa propriedade rural (localizada a uma latitude 20 59'36" Sul e a uma longitude $51^{\circ} 16^{\prime} 39^{\prime \prime}$ Oeste), noroeste paulista. O clima da região é quente no verão $\left(33^{\circ} \mathrm{C}-37^{\circ} \mathrm{C}\right)$ e com chuvas $(28 \mathrm{~mm}-70 \mathrm{~mm})$. No inverno com temperaturas amenas $\left(22^{\circ} \mathrm{C}-25^{\circ} \mathrm{C}\right)$ com estiagem $(9 \mathrm{~mm}-12 \mathrm{~mm})$. O local do experimento foi em condição de viveiro, 50\% de luminosidade com irrigação manual com uso de mangueiras duas vezes ao dia.

O delineamento utilizado foi inteiramente casualizado, com 4 repetições 48 sementes por parcela. Os dados obtidos foram submetidos à análise de variância, sendo os dados qualitativos comparados pelo teste de Tukey no nível de 5\% de probabilidade e os quantitativos. As análises foram realizadas pelo programa computacional SISVAR (FERREIRA, 2000). Os dados de porcentagem de germinação foram 
transformados em arc seno $\sqrt{x}_{\mathrm{x}} / 100$ para a normalização de sua distribuição (Bartlett 1947).

Foram utilizadas sementes de seriguela (Spondias purpurea L.), extraídas de uma planta matriz da propriedade, com aproximadamente 17 anos de idade. O endocarpo foi extraído da semente, por meio de lavagem em água corrente até a completa eliminação de resíduos. Após retirada a polpa dos frutos, foi realizado um processo de assepsia das sementes, em solução de álcool 70\% (v/v) durante 1 minuto, e em hipoclorito de sódio $(2,5 \%)$ por 1 minuto sendo lavadas em água corrente. Logo em seguida, as sementes foram secas em papel toalha e deixadas na sombra para finalizar a secagem em peneira, por um período de $12 \mathrm{~h}$. No dia seguinte deu-se início ao processo de classificação das sementes, onde as mesmas, foram medidas com paquímetros, entre as extremidades das sementes e pesadas em balança convencional, dando origem a grupos bem definidos e homogêneos:

a) Grupo 1 - sementes pequenas e leves $(1-3 \mathrm{~cm}$ de comprimento e 5-10g).

b) Grupo 2 - sementes grandes e pesadas (acima de $3 \mathrm{~cm}$ de comprimento e acima de $10 \mathrm{~g}$ );

As medições foram realizadas com paquímetros, entre as extremidades das sementes e a massa em balança de precisão. As sementes foram semeadas em saquinhos plásticos com capacidade de $1 \mathrm{~kg}$, sendo plantadas em profundidades de até $5 \mathrm{~cm}$, cobrindo as sementes completamente com substrato, terra + esterco bovino na proporção (3:1) ou areia de construção + esterco bovino na proporção (3:1). A irrigação foi realizada manualmente, duas vezes ao dia, temperatura ambiente e viveiro aberto com telado sombrite cobrindo o ripado

A avaliação da germinação foi realizada diariamente, considerando-se germinada a semente que rompesse o tegumento e emitisse radícula com pelo menos $2 \mathrm{~mm}$ de comprimento durante os 60 dias após o plantio. Foi avaliada a porcentagem de germinação (PG), o comprimento médio da plântula (CP) e massa da matéria seca de plântulas (MMS), bem como o índice de velocidade de germinação (IVG), empregando-se a fórmula proposta por MAGUIRE (1962) citado por RANZANI et al., (2016).

As contagens das sementes germinadas foram efetuadas diariamente, no mesmo horário, durante o período de 48 dias para determinação da porcentagem de germinação (PG). As plântulas foram removidas dos substratos 60 dias após a semeadura. Comprimento médio da plântula foi obtido somandose as médias de cada repetição e pelo número plântulas mensuradas, com resultados expressos em centímetros (cm), conforme descritos por NAKAGAWA (1999).

Após a determinação da massa fresca das plântulas, estas foram acondicionadas em sacos de papel e secadas em estufa de circulação forçada de ar a $60^{\circ} \mathrm{C}$, até a obtenção de massa constante (48h). O material seco foi pesado em balança de precisão 0,001g, sendo os resultados de massa da matéria seca de plântulas (MS) expressos em miligramas (mg) por plântula, conforme NAKAGAWA (1999) e SILVA \& CESARINO (2016). O índice de velocidade de germinação (IVG) foi determinado empregando-se a fórmula proposta por MAGUIRE (1962) citado por RANZANI et al. (2016).

\section{Resultados e Discussão}

$\mathrm{Na}$ tabela 01 pode-se constatar os resultados para os tipos de sementes, sobre as características avaliadas $(\mathrm{P}>0,05)$ como porcentagem de germinação, índice de velocidade de germinação comprimento médio das plântulas e massa da matéria seca, não havendo diferença significativa entre as sementes e os tipos de substratos, mostrando que os tipos de substratos não interferem na germinação dos dois grupos de sementes estudadas. 
Tabela 01: Resumo da análise de variância.

\begin{tabular}{lccccc}
\cline { 3 - 6 } Fonte de Variância & \multicolumn{5}{c}{ QM } \\
\cline { 2 - 6 } & GL & \% Germinação & \multicolumn{1}{c}{ IVG } & CP & \multicolumn{1}{c}{ MMS } \\
\hline Sementes & 1 & $18406,3680^{*}$ & $1,846336^{*}$ & $13,34^{*}$ & $0,0388^{*}$ \\
Substratos & 2 & 12,86783 ns & $0,0585^{\text {ns }}$ & $7,34^{\text {ns }}$ & $0,0015^{\text {ns }}$ \\
Sx S & 3 & $168,75233^{*}$ & 0,10264 ns & 3,82 ns & $0,0017^{*}$ \\
Resíduos & 4 & 179,68275 & 0,02140 & 7,62 & 0,0008 \\
\hline
\end{tabular}

(*) significativo pelo teste $\mathrm{F}$ a $5 \%$ de probabilidade; (ns) não significativo pelo teste $\mathrm{F}$ a $5 \%$ de probabilidade. $\mathrm{GL}=$ graus de liberdade; $\mathrm{QM}=$ quadrado médio.

Em relação à porcentagem de germinação de sementes de seriguela e a influência do comprimento e da massa percebe-se que houve efeito significativo para os dois grupos de sementes (pequenas) e (grandes) conforme podemos observar na tabela 02. Através das médias, percebemos que as sementes grandes apresentaram maiores porcentagens de germinação, índice de velocidade, comprimento da plântula e massa seca. Este fato vem ao encontro dos resultados obtidos por CARVALHO e NAKAGAWA, (2000), HÖFS et al., (2004), SILVA et al., (2010), FLORES et al., (2014).

Para Silva et al., (2010) trabalhando com germinação de sementes pequenas e grandes de jaqueira (Artocarpus heterophyllus Lam.) o tamanho das sementes influenciou a porcentagem de germinação da jaqueira, observou-se que a classe de sementes pequenas obteve germinação de $70 \%$, esta diferiu estatisticamente dos demais tratamentos, já as sementes médias, grandes e extragrandes apresentaram 88\%, 96\% e 98\% respectivamente, não diferindo entre si.

O tamanho das sementes também foi estudado para as espécies Mimosa caesalpiniaefolia (Alves et al., 2005), Syzygium malaccense (Costa et al., 2006), Schizolobium amazonicum (Ghisolfi et al., 2006), Hyptis suaveolens (Mandal et al., 2008), Ricinus communis (Lucena et al., 2008) e Caesalpinia leiostachya (Biruel et al., 2010), verificando-se que, em geral, sementes grandes apresentaram maiores porcentagem de germinação e vigor. Além disto, citam o incremento do $\mathrm{GA}_{3}$ na porcentagem de germinação, índice de velocidade de germinação e massa seca das plântulas nas diferentes concentrações.

A importância do tamanho das sementes tem sido relatada em uma série de artigos, dentre elas destacam-se, Carvalho e Nakagawa (2000) pelo fato de constituir um dos fatores que podem influenciar a germinação e o vigor das plântulas. As sementes de maior tamanho, que apresentam maior densidade, durante seu desenvolvimento foram as mais nutridas. Este fato torna-se mais patente nas plantas cujas sementes não são formadas todas ao mesmo tempo, de sorte que as últimas a se desenvolverem são, normalmente, menores, ou de menor densidade.

Por este motivo, as maiores e as de maior densidade são as que possuem, normalmente, embriões bem formados e com maiores quantidades de reservas sendo, potencialmente, as mais vigorosas e com maior capacidade de sobrevivência. Assim, é razoável que uma cultura apresente, em condições de campo, populações de plantas diferentes em favor das sementes maiores (CARVALHO e NAKAGAWA, 2000; PÁDUA et al., 2010). A maior quantidade de reserva aumenta a probabilidade de sucesso no estabelecimento da plântula (Haig e Westoby, 1991), pois permite a sobrevivência por maior tempo em condições ambientais desfavoráveis.

De acordo com Carvalho e Nakagawa (2000) as sementes de maior tamanho possuem embriões bem formados e com maior quantidade de substâncias de reserva, sendo, consequentemente, as 
mais vigorosas. Wagner Junior et al., (2008) descrevem que o crescimento das plântulas em altura deve-se à capacidade dos fito-hormônios como o ácido giberélico $\left(\mathrm{GA}_{3}\right)$ endógeno presentes nas sementes de estimular a expansão do caule. Segundo esses autores esta expansão é consequência da elongação das células e não do aumento na divisão celular. Provavelmente, o maior crescimento foi consequência do alongamento celular, o que refletiu no crescimento em altura, sem que fosse detectado aumento no diâmetro do caule comparando as doses aplicadas.

Tabela 02: Porcentagem de Germinação (\%), Índice de velocidade de germinação (IVG), comprimento médio da plântula (CP) e a massa seca (MMS) da plântulas de seriguela (Spondias purpurea L.).

\begin{tabular}{lllll}
\hline TRATAMENTOS & $\% \mathrm{G}$ & IVG & \multicolumn{1}{c}{ CP } & MMS \\
\hline Sementes pequenas e leves & $47,40 \mathrm{~b}$ & $5,98 \mathrm{~b}$ & $7,25 \mathrm{~b}$ & $0,345 \mathrm{~b}$ \\
Sementes grandes e pesadas & $81,62 \mathrm{a}$ & $8,45 \mathrm{a}$ & $10,25 \mathrm{a}$ & $0,874 \mathrm{a}$ \\
\hline $\mathrm{CV}(\%)$ & 2,03 & 1,45 & 2,06 & 1,03 \\
\hline
\end{tabular}

As médias seguidas da mesma letra na coluna não diferem entre si pelo teste de Tukey, a $5 \%$ de probabilidade.

Não foram detectados efeitos dos tipos de substratos para as variáveis percentuais de germinação, índice de velocidade de germinação, comprimento das plântulas e nem massa seca das plântulas (Tabela 03). Independe do tipo de substrato utilizado a potencialidade e a capacidade fisiológica de germinação das sementes, estão correlacionadas com presença da matéria orgânica no substrato, características morfológicas das sementes e sua potencialidade genética (BECKMANN-CAVALCANTE et al., 2012; FIOR et al., 2013; FIRMINO et al., 2015, SANTOS et al., 2018).

Os resultados obtidos na tabela 03 estão de acordo com Martins et al., (2011) testando diferentes tipos de substratos para a germinação de PalmeiraReal-Australiana (Archontophoenix alexandrae H. Wendl. $\&$ Drude) verificaram que os melhores resultados para a porcentagem de germinação, foram nos tratamentos com substrato vermiculita.

Charlo et al. (2006) verificaram que a utilização de Plantmax ${ }^{\circledR}$ como substrato para a produção de mudas em viveiro promoveu maior desenvolvimento das raízes e emergência das plântulas do que o uso do substrato areia com terra e as misturas de proporções iguais de terra, areia e esterco; esses autores consideraram que as condições mais adequadas para a germinação dessas sementes estariam relacionadas com a umidade e aeração dos substratos. Pivetta et al. (2008) verificaram que a vermiculita foi o substrato mais adequado para a germinação (Archontophoenix cunninghamii H. Wendl. \& Drude), em comparação com areia e esfagno.

Além das condições de climáticas adequada para cada espécie, Bovolini et al., (2015), citam que o substrato é um elemento importante e determinante para a germinação das sementes. Suas características físicas como, a capacidade de retenção de água, porosidade total, espaço de aeração e estrutura proporcionam condições favoráveis para a germinação das sementes, desenvolvimento e sustentabilidade das plântulas. A escolha do tipo de substrato a ser utilizado deve levar em consideração o tamanho da semente, sua exigência com relação à água, sensibilidade à luz, e que propicie facilidade para o desenvolvimento e avaliação das plântulas.

No entanto, para as condições do experimento o tipo de substrato não interferiu nas variáveis, mas os tipos de sementes utilizadas, vindo de encontro com os resultados obtidos por MIRANDA et al., (2012) e MACIEL et al. (2013) que ao trabalharem 
com germinação de sementes de Anadenanthera peregrina (L.) Speg e Jacaranda mimosifolia (L.) notaram efeito significativo na porcentagem de germinação a semeadura sobre papel-filtro e em vermiculita favoreceram o índice de velocidade de germinação das sementes das respectivas espécies. Já os demais tipos de substratos não interferiram na porcentagem de germinação e no índice de velocidade de germinação.

Pagliarin et al., (2014) com objetivo de avaliar a influência do tamanho de sementes e dos substratos na germinação de sementes e biometria de plântulas de jatobá (Hymeneae courbaril L. var. Stilbocarpa), verificaram que o tamanho, massa e substrato interferem na porcentagem de germinação, altura das plantas, diâmetro médio do caule das plantas, e relação altura de planta e diâmetro de caule, sugerindo que para a produção de mudas de jatobá deve-se utilizar sementes médias ou grandes em vermiculita ou substrato comercial. Dentre os resultados obtidos destacam-se 72,5\% (médias) e 87,5\% (grandes) de germinação nas sementes médias e grandes nos substratos comerciais. Já no substrato areia de construção a média da porcentagem de germinação foi de $17,5 \%$.
Cunha et al., (2018) citam que o substrato se destaca e exerce papel fundamental no desempenho germinativo das sementes. Ele detém a função de manter as condições adequadas para germinação das mesmas e para o desenvolvimento das plântulas. Os autores citados ao trabalharem com cinco tipos de substratos no crescimento inicial de Barú (Dipteryx alata Vog.) notaram que o uso de substrato formulado com terriço floresta propicia mudas de baru com maior qualidade para o campo. Segundo Queiroz \& Firmino (2014) além de fornecer água, oxigênio e nutrientes, permitindo o crescimento das raízes e assim consequentemente oferecendo suporte estrutural à parte aérea.

Vale ressaltar, que o desenvolvimento em relação ao vigor das plântulas (altura, diâmetro do colo, comprimento das plântulas e massa seca das plântulas) constituem um dos parâmetros usados para avaliar a qualidade de mudas florestais, pois, além de refletir o acúmulo de reservas, proporciona também maior resistência e melhor fixação no solo. Essa variável é reconhecida como um dos melhores indicadores do padrão de qualidade de mudas, sendo, em geral, o mais indicado para determinar a capacidade de sobrevivência de mudas no campo (ARAUJO et al., 2018).

Tabela 03: Tipos de substratos e sua interferência na porcentagem de Germinação (\%), Índice de velocidade de germinação (IVG), comprimento médio da plântula (CP) e a massa seca (MS).

\begin{tabular}{lccll}
\hline TRATAMENTOS & $\%$ Germinação & IVG & CP & MMS \\
\hline Sementes pequenas e leves & & & & \\
Terra + esterco bovino & $48,25 \mathrm{aB}$ & $5,89 \mathrm{aB}$ & $7,22 \mathrm{aB}$ & $0,355 \mathrm{aA}$ \\
Areia + esterco bovino & $46,55 \mathrm{aB}$ & $5,75 \mathrm{aB}$ & $7,05 \mathrm{aB}$ & $0,342 \mathrm{aA}$ \\
\hline CV $(\%)$ & 1,13 & 1,05 & 1,55 & 1,23 \\
\hline Sementes grandes e pesadas & & & & \\
Terra + esterco bovino & $82,50 \mathrm{aA}$ & $8,48 \mathrm{aA}$ & $9,98 \mathrm{aA}$ & $0,857 \mathrm{aA}$ \\
Areia + esterco bovino & $80,75 \mathrm{aA}$ & $8,42 \mathrm{aA}$ & $9,85 \mathrm{aA}$ & $0,854 \mathrm{aA}$ \\
\hline CV $(\%)$ & 1,08 & 1,10 & 2,03 & 1,08 \\
\hline
\end{tabular}

As médias seguidas da mesma letra na coluna não diferem entre si pelo teste de Tukey, a 5\% de probabilidade.

É importante destacar que trabalho de germinação de sementes tendo como substrato somente por solo de cerrado, pode ser prejudicial a porcentagem de germinação, índice de velocidade de germinação e ao vigor das mudas, pois sendo um solo naturalmente ácido e de baixa fertilidade, inibe o 
crescimento radicular, alongamento celular e a absorção nutricional, fato que pode explicar o baixo crescimento das plantas submetidas a este tratamento (CABRAL et al., 2016). Na tabela 3 pode-se constatar que não houve interações entre os tipos de sementes, mostrando que os tipos de substratos não interferem nas variáveis estudadas.

\section{CONCLUSÃO}

Sementes pequenas apresentam germinação e índice de velocidade de germinação inferiores às sementes grandes. O tipo de substrato não interferiu na porcentagem de germinação, índice de velocidade de germinação, comprimento das raízes e massa seca das plantas de (Spondias purpurea L.).

\section{REFERENCIAS BIBLIOGRÁFICAS}

ALMEIDA, J. P. N.; LEITE, G. A.; MENDONÇA, V.; CASTRO FREITAS, P. S.; ARRAIS, I. G.; SILVA TOSTA, M. Concentrações de AIB e substratos no enraizamento e vigor de estacas lenhosas de cajaraneira. Revista de Ciências Agrárias, Belém, v. 60, n. 1, p. 11- 18. 2017.

ALVES, E. U; BRUNO, R. de L. A.; OLIVEIRA, A. P. de; ALVES, A. U.; ALVES, A. U.; PAULA, R. C. de Influência do tamanho e da procedência de sementes de Mimosa caesalpiniaefolia Benth. sobre a germinação e vigor. Revista Árvore, Viçosa, MG, v. 29, n. 6, p. 877-885, 2005.

ARAUJO, M. S.; D’ABADIA, K. L.; CUNHA, S. D.; COELHO, G. M. MORAIS, Y. C. R.; BARRETTTO, V. C. M.; CALIXTO JUNIOR, J. E. D. Efeitos da fertilização potássica no crescimento inicial de Khaya senegalensis (A). (Juss) no bioma Cerrado. Ecologia e Nutrição Florestal, v. 6, n. 1, p. 8-16, 2018.

BARTLET'T, M.S. The use of transformations. Biometrics, Arlington, v. 3, p. 39-52, 1947.

BECKMANN-CAVALCANTE, M. Z.; PIVET'TA, K. F. L.; IHA, L. L.; TAKANE, R. J. Temperatura, escarificação mecânica e substrato na germinação de sementes das palmeiras juçara e açaí. Revista Brasileira de Ciências Agrárias. v.7, n.4, p.569-573, 2012.

BIRUEL, R. P.; PAULA, R. C. de; AGUIAR, I. B. de. Germinação de sementes de Caesalpinia leiostachya (Benth) Ducke (pau-ferro) classificadas pelo tamanho e pela forma. Revista Árvore, v. 34, n. 2, p. 197-204, 2010.

BOVOLINI, M.P; MACIEL, C.G; BRUM, D.L; MUNIZ, M.F.B. Influência de temperatura e substrato na germinação e no vigor de sementes de Jacaranda micrantha Cham. Revista de Ciências Agroveterinárias, Lages, v.14, n.3, p.203-209, 2015.

CABRAL, C. E. A.; CABRAL, L. S.; SILVA, E. M. B.; CARVALHO, K. S. C.; KROTH, B. E.; CABRAL, C. H. A. Resposta da Brachiaria brizantha $\mathrm{cv}$. Marandu a fertilizantes nitrogenados associados ao fosfato natural reativo. Comunicata Scientiae, v.7, n.1, p.66-72, 2016.

CARVALHO, N.M.; NAKAGAWA, J. Sementes: ciência, tecnologia e produção. Funep: Jaboticabal, 588p. 2000.

CHARLO, H. C. O. et al. Aspectos morfológicos, germinação e desenvolvimento inicial de plântulas de Archontophoenix alexandrae (F. Mueller) H. Wendl. e Drude (Arecaceae) em diferentes substratos. Revista Árvore, v.30, n.6, p.933-940, 2006.

COSTA, R. S.; OLIVEIRA, I. V. de M.; MÔRO, F. V.; MARTINS, A. B. G. Aspectos morfológicos e influência do tamanho da semente na germinação do jambo-vermelho. Revista Brasileira de Fruticultura, Jaboticabal, v. 28, n. 1, p. 117-120, 2006

CUNHA, S. D.; SOUZA, S. A. G.; ARAUJO, M. S.; DABADIA, K. L.; MORAIS, Y. C. R. Substratos no crescimento inicial de mudas de baru. Agrarian academy, Goiânia, v. 5, p. 191-199, 2018.

FERREIRA, A.; COSTA, J.D.P.; SOUSA, S., RIBEIRO, L.; COSTA, J. Comportamento higroscópico de polpa de seriguela atomizada utilizando diferentes agentes carreadores de secagem. Chemical Engineering Proceedings, v. 1, n.2, p. 3900-3907, 2015. 
FERREIRA, D.F. Análise estatística por meio do SISVAR (Sistema para Análise de Variância) para Windows versão 4.0. In: REUNIÃO ANUAL DA REGIÃO BRASILEIRA DA SOCIEDADE INTERNACIONAL DE BIOMETRIA, 45., 2000, São Carlos. Anais... São Carlos: UFSCar, p.255-258. 2000.

FIOR, C. S.; SOUZA, P. V. D.; SCHWARZ, S. F. Emergência de plântulas de Butia odorata (Barb. Rodr.) Noblick em casa de vegetação. Revista Árvore, Viçosa-MG, v.37, n.7, p.503-510, 2013.

FIRMINO, J.L; ALMEIDA, M.C; BARBOSA, C.S; FERREIRA, E.J.L. Efeito de diferentes substratos na germinação e vigor de sementes de Chelyocarpus chuco (Arecaceae). ENCICLOPÉDIA BIOSFERA, Centro Científico Conhecer. v.11 n.21; p.888-897, 2015.

FLORES, A.V; BORGES, E.E.L; GONCALVES, J.F.C; GUIMARÃES, V.M; ATAÍDE, G.M; BARROS, D.P; PEREIRA, M.D. Efeito do substrato, cor e tamanho de sementes na germinação e vigor de Melanoxylon braúna. Pesquisa Florestal Brasileira, v. 34, n. 78, p. 141-147, 2014.

GHISOLFI, E.M; EFFGEN, E.M; MENDONÇA, A.R; NAPPO, M.E; SILVA, A.G. INFLUÊNCIA DO TAMANHO DA SEMENTE E TIPO DE RECIPIENTE NA GERMINAÇÃO DE Schizolobium amaźnicum (Herb) Ducke. Revista Científica Eletrônica de Agronomia. v.5, n.09, p.1-7, 2006.

HAIG, D.; WESTOBY, M. Seed size, pollination casts and angiosperm success. Evolutionary Ecology, v. 5, p. 231-247, 1991.

HÖFS, A.; SCHUCH, L. O. B.; PESKE, S. T. Emergência e crescimento de plântulas de arroz em resposta á qualidade fisiológica de sementes. Revista Brasileira de Sementes, v. 26 n. 1, p. 92-97. 2004.

LEDERMAN, I. E.; SILVA, J. F. J.; BEZERRA, J. E. F.; LIRA, J. S. J. Potencialidade das espécies de Spondias no desenvolvimento da fruticultura brasileira. In: LEDERMAN, I. E.; LIRA JÚNIOR, J. S.; SILVA JÚNIOR, J. F. Spondias no Brasil: umbú, cajá e espécies afins. Anais... Recife: UFRPE, 2008. p.15-22.
LIMA, T.L.B; SILVA; R.M; CARNEIRO, E.F.S; SILVA, S.N; FIGUEIRÊDO, R.F. Avaliação físico-química do fruto de seriguela verde proveniente de pomar doméstico rural. Congresso Técnico Científico da Engenharia e da Agronomia CONTECC'2018. Anais... Maceio:UFCE, p. 21-24, 2018.

LIRA JÚNIOR, J.S; BEZERRA, J.E.F; MOURA, J.O.M; SANTOS, V.F. Repetibilidade da produção, número e peso de fruto em cirigueleira (Spondias purpurea L.). Revista Brasileira Fruticultura. v. 36, n. 1, p. 214-220, 2014

LUCENA, A. M. A. de; SEVERINO, L. S.; BELTRÃO, N. E. de M.; SOFIATTI, V.; MEDEIROS, K. A. L.; OLIVEIRA, M. I. P. de; BORTOLUZI, C. R. D. Influência do estádio de maturação da semente e da profundidade de semeio I: emergência das plântulas e área foliar dos cotilédones. In: CONGRESSO BRASILEIRO DE MAMONA, 3., 2008, Salvador. Energia e ricinoquímica: resumos. Salvador: SEAGRI: Embrapa Algodão, p. 99. 2008.

MACIA, M. J.; BARFOD, A.S. Economic botany of Spondias purpurea L. (Anacardiaceae) in Ecuador. Economic Botany, Saint Louis, v. 54, n.4, p. 449- 458. 2000.

MACIEL, C.G. et al. Avaliação de Temperaturas e Substratos na Germinação de Sementes de Jacaranda mimosifolia. Floresta Ambient. v.20, p.55-61. 2013.

MAGUIRE J.D. Seep of germination-aid seedling emergence and vigor. Crop Science, v.2, p.176177, 1962.

MALDONADO-ASTUDILLO, Y. I.; ALIATEJACAL， I.; NÚÑEZ-COLÍN， C. A.; JIMÉNEZ-HERNÁNDEZ， J.; PELAYOZALDÍVAR, C.; LÓPEZ-MARTÍNEZ, V.; ANDRADERODRÍGUEZ, M.; BAUTISTABAÑOS, S.; VALLE-GUADARRAMA, S. Postharvest physiology and technology of Spondias purpurea L. and S. mombin L. Scientia Horticulturae, v.174, n.1, p.193-206, 2014.

MANDAL, S. M.; CHAKRABORTY, D.; GUPTA, K. Seed size variation: influence on germination and subsequent seedling performance in Hyptis suaveolens (Lamiaceae). Research Journal of Seed Science, New York, v. 1, n. 1, p. 26-33, 2008. 
MARTINS, C.C; CALDAS, I.G.R; MACHADO, G.C; DOURADO, W.S. Tipos de substratos para germinação de sementes de palmeira- realaustraliana (Archontophoenix alexandrae H. Wendl. \& Drude). Revista Árvore. v.35, n.6, p.11891196, 2011.

MARTINS, L.P.; SILVA, S. de M.; ALVES, R.E.; FILGUEIRAS, H.A.C. Desenvolvimento de frutos de cirigueleira (Spondias purpúrea L.). Revista Brasileira de Fruticultura, v. 25, n. 1, p. 11-14, 2003.

MIRANDA C. C. et al. Germinação de sementes de Anadenanthera peregrina (L.) Speg. com diferentes substratos em condições laboratoriais. Floresta Ambiental. 19: 26-31. 2012.

NAKAGAWA, J. Testes de vigor baseados no desempenho de plântulas. In: KRZYZANOWSKI, F.C.; VIEIRA, R.D.; FRANÇA NETO, J.B. (Ed.) Vigor de sementes: conceitos e testes. Londrina: Abrates. p.1-24. 1999.

PÁDUA, G.P; ZITO, R.K; ARANTES, N.E; FRANÇA NETO, J.B. Influência do tamanho da semente na qualidade fisiológica e na produtividade da cultura da soja. Revista Brasileira de Sementes, vol. 32, no 3 p. 009016, 2010.

PAGLIARINI, M.K; NASSER, M.D; NASSER, F..A.C.M; CAVICHIOLI, J.C; CASTILHO, R.M.M. Influência do tamanho de sementes e substratos na germinação e biometria de plântulas de jatobá. Revista Tecnologia \& Ciências Agropecuária. v.8, n.5, p.33-38, dez. 2014

PIVETTA, K. F. L. et al. Tamanho do diásporo, substrato e temperatura na germinação de sementes de Archontophoenix cuninghamii. Revista de Biologia e Ciências da Terra, v.8, n.1, p. 126-134, 2008.

QUEIROZ, S. E. E.; FIRMINO, T. O. Efeito do sombreamento na germinação e desenvolvimento de mudas de baru (Dipteryx alata Vog.). Revista Biociências, v. 20, n. 1, p. 72-77, 2014.

RANZANI, R.E; LUZ, P.B; MAROSTEGA, T.N. PAIVA S. S. Efeitos de diferentes substratos e temperaturas na germinação de sementes de
Foeniculum vulgare. Revista Brasileira de Plantas Medicinais, v.18, n.1, supl. I, p.363-366, 2016.

ROCHA, G.T; SILVA, A.G; PEIXOTO, N; MARTINS, J.B; RODRIGUES, F. Vegetative propagation of red mombin (Spondias purpurea) with immersion in indole-3-acetic acid. Revista Brasileira de Ciências Agrárias. v.14, n.2, e5650, 2019

SACRAMENTO, C. K.; SOUZA, F. X. CAJÁ. IN: SANTOS-SEREJO, J. A.; DANTAS, J. L. L.; SAMPAIO, C. V.; COELHO, Y. S. Fruticultura tropical: espécies regionais e exóticas. Brasília: Embrapa Informação Tecnológica, p.83-105. 2009.

SANTOS, P.L.F; PAIXÃO, A.P; SILVA, O.N.M; CASTILHO, R.M.M. Germinação de sementes e desenvolvimento de plântula de abóbora em substratos e bandejas. Revista Tecnologia \& Ciência Agropecuária. v.12, n.1, p.57-64, 2018.

SILVA, B.M.S; CESARINO, F; Germinação de sementes e emergência de plântulas de jutaí (Hymenaea parvifolia Huber.). Revista Brasileira Plantas Medicinais, v.18, n.1, supl. I, p.256263, 2016

SILVA, K.S; MENDONCA, V; MEDEIROS, L.F; FREITAS, P.S.C; GÓIS, G.B; Influência do tamanho da semente na germinação e vigor de mudas de jaqueira (Artocarpus beterophyllus Lam.). Revista Verde. v.5, n.4, p. 217 - 221, 2010.

SOUZA, A.F.F; COELHO JUNIOR, M.G; NOGUEIRA, J.K.S; SILVA NETO, E.C; CARVALHO, A.G. Propagação vegetativa por estaquia de serigueleira (Spondias purpurea L.) com diferentes concentrações de ácido indolbutírico. Revista Agropecuária Científica no Semiárido (ACSA) v.14, n.3, p.234-239, 2018.

WAGNER JÚNIOR, A; SILVA, J.A.C; SANTOS, C.E.M; PIMENTEL, L.D; NEGREIROS, J.R.S; BRUCKNER, C.H. Ácido giberélico no crescimento inicial de mudas de pessegueiros. Ciências Agrotecnológico. v. 32, n. 4, p. 1035 1039, 2008. 